\title{
ENOXAPARIN FOR THROMBOSIS IN NEONATES: PRELIMINARY REPORT
}

\author{
Fiammetta PIERSIGILLI ${ }^{1}$, Cinzia AURITI ${ }^{1}$, Mary HAYWOOD LOMBARDI ${ }^{1}$, Giusi PRENCIPE², \\ Francesca CAMPI ${ }^{1}$, Andrea DOTTA ${ }^{1}$
}

\author{
${ }^{1}$ Department of Neonatology, Bambino \\ Gesù Children's Hospital, Rome, Italy \\ ${ }^{2}$ Division of Research Laboratory, Bambino \\ Gesù Children's Hospital, Rome, Italy \\ Corresponding author: \\ Fiammetta Piersigilli \\ Department of Neonatology \\ Bambino Gesù Children's Hospital \\ Piazza S. Onofrio 4 \\ 00165 ROME, ITALY \\ fiammetta.piersigilli@opbg.net \\ Tel.: + 390668592427 \\ Fax.: + 39063313309
}

Received: March 17, 2013

Accepted: August 8, 2013

Copyright (C) 2013 by

University Clinical Center Tuzla.

E-mail for permission to publish:

paediatricstoday@ukctuzla.ba

\begin{abstract}
Objectives - To investigate the dose of enoxaparin required in neonates to achieve target therapeutic ranges of anti factor Xa 48 hours after starting therapy, and compare this dose to recommended guideline dosages for neonates. Methods - We retrospectively reviewed 19 records of newborns who received enoxaparin at different doses for the treatment of thrombosis and evaluated how many among them reached the target anti-factor Xa level after 48 hours. Results - Only $1 / 5$ neonates $(20 \%)$ treated with $150 \mathrm{UI} / \mathrm{kg}$ twice a day, but $100 \%$ $(6 / 6)$ of those treated with $175 \mathrm{UI} / \mathrm{kg}$ twice a day reached therapeutic levels of anti-factor Xa at 48 hours. Of the 8 neonates treated with lower starting doses none reached the therapeutic range after 48 hours and these required the highest number of dose changes. Conclusions - Our results reinforce the need to increase in neonates the dosage of enoxaparin suggested in published guidelines, in order to shorten the time-delay in achieving a therapeutic level of anti-factor Xa, and also reducing the number of blood tests necessary for dosing anti-factor Xa.
\end{abstract}

Key words: Enoxaparin - Neonatal thrombosis - Factor Xa level NICU.

\section{Introduction}

The incidence of symptomatic thrombosis is 5.1 per 100000 live births (1) and 2.4 per 1000 neonatal intensive care admissions (2). Thrombosis occurs more frequently in the neonatal period than in any other period of childhood. In fact the haemostatic system of the neonate is immature and in continuous development. In the critically ill neonate additive factors may contribute to the development of thrombosis: the presence of indwelling catheters is the single, greatest risk factor for arterial or venous thrombosis; dehydra- tion, sepsis, maternal diabetes and asphyxia are other risk factors (2). Congenital thrombophilia can also enhance the risk of thromboembolic events in neonates.

Until recently, the current treatment of thrombosis consisted of administration of unfractionated heparin followed by oral anticoagulants. As low molecular weight heparin (LMWH) has significant advantages over those treatments [more predictable pharmacokinetics reducing the need for monitoring patients, lesser bleeding, lesser thrombocytopenia and lesser osteopenia compared to UFH (3)] it has currently become the medi- 
cation of choice for the prevention and treatment of thrombosis.

Initially the dosage of enoxaparin, the most used LMWH, was extrapolated from experience in adults and older children (100 UI/kg subcutaneously twice a day). Subsequent studies indicated that infants under 2 months of age have higher dose requirements than adults and older children to achieve and maintain the therapeutic effect (4). In 2008, the American College of Chest Physicians published practice guidelineS for antithrombotic therapy in neonates, and the recommended dose of enoxaparin consisted of 150 $\mathrm{UI} / \mathrm{kg}$, administered subcutaneously twice in a day, followed by titration of the dose according to the plasma anti-factor Xa level (5). This dosage was confirmed in the upgraded guidelines published in 2012 (6). However recent studies (7) recommend higher initial doses for neonates and preterm infants.

To investigate if even our neonates needed higher doses of enoxaparin than those currently recommended to achieve target therapeutic ranges of anti factor $\mathrm{Xa} 48$ hours after starting therapy, we reviewed retrospectively the medical records of neonates with thrombosis admitted to our NICU during a period of 42 months who were treated with enoxaparin.

\section{Methods}

The medical records of all neonates with venous or arterial thrombosis between January 2007 and June 2011 were retrospectively examined. This study was classified as a clinical audit, approved by our Institution Review Board. The main outcome measure of the study was the dose of enoxaparin required to achieve an anti factor Xa level in the range $0.5-1 \mathrm{U} / \mathrm{ml}$, which is considered to be the therapeutic range (5). Secondary outcomes were the presence of bleeding complications (intraventricular haemorrhage, pulmonary haemorrhage, ematemesis) and thrombocytopenia (platelet count $<150.000 / \mathrm{mm}^{3}$ ).

Data collected included patient demographics, clinical characteristics (birth weight, gestational age), placement of venous and/or arterial catheters at birth or later, progression of thrombosis, enoxaparin dosages with corresponding anti factor Xa levels, and adverse events (bleeding, thrombocytopenia, osteoporosis).

Before starting anticoagulation, all patients underwent a cranial ultrasound, blood exams and platelet count. In all cases, diagnosis of arterial or venous thrombosis was made on the basis of a radiologic evaluation (a doppler ultrasound and if necessary an angio-tomography). All anti Xa concentrations were drawn 4 hours after the fourth dose of enoxaparin. As in our institution we do not use continuous infusion of Heparin in the catheters, the sample was drawn peripherically or obtained through the catheter. If the level was below the therapeutic range, the dose was adjusted by $10 \%$, and the antifactor Xa level was measured again after 3 doses until the desired concentrations were obtained. The maintenance dose was adjusted weekly for weight gain.

Initially we used to treat our patients with $100 \mathrm{UI} / \mathrm{kg}$ every 12 hours, but as with this scheme of increasing dose adjustment the majority of neonates were not able to reach therapeutic levels (the maximum dose that we administered was $150 \mathrm{UI} / \mathrm{kg}$ every 12 hours), as time went on we gradually increased the initial dose of subsequent patients to $110,130,150$ and finally to $175 \mathrm{UI} / \mathrm{kg}$ every 12 hours.

The efficacy of treatment was determined by clot resolution, as established by ultrasonography or echocardiography.

\section{Results}

We reviewed the clinical records of 19 neonates (13 at term, mean GA 39 weeks, mean 
birth weight $3.315 \mathrm{~g}$ and 6 preterm, mean GA 30 weeks, mean birth weight $1.503 \mathrm{~g}$ ). Seventeen neonates had a catheter at time of diagnosis of thrombosis or prior to diagnosis, whereas in 2 neonates no catheter had ever been positioned.

Of the 8 neonates treated with starting doses lower than $150 \mathrm{UI} / \mathrm{kg}$ none reached the therapeutic range after 48 hours from the start of therapy and these neonates required the highest number of dose changes. Only $1 / 5$ neonates $(20 \%)$ treated with $150 \mathrm{UI} / \mathrm{kg}$ twice a day as initial dose, but $100 \%(6 / 6)$ of those treated with $175 \mathrm{UI} / \mathrm{kg}$ twice a day as initial dose reached therapeutic levels of antifactor Xa at 48 hours.

The mean dose that produced therapeutic anti factor Xa level was $180 \mathrm{UI} / \mathrm{kg}$ every 12 hours (range 150-220 UI/kg). Neonates starting with $100 \mathrm{UI} / \mathrm{kg}$ every 12 hours needed more than five days to achieve a therapeutic dosage and 3 neonates (15.8\%) never reached the desired level of anti factor Xa. Preterm infants seemed to require a higher dose compared with term infants in order to achieve therapeutic anti-factor Xa levels (mean $190 \mathrm{UI} / \mathrm{kg}$ every $12 \mathrm{hrs,} \mathrm{range}$ 175-220 UI/kg).

Eleven out of nineteen (57.8\%) thromboembolic events resolved completely. Five out of $7(71.4 \%)$ neonates who reached anti-factor Xa therapeutic level immediately after 48 hours had a complete resolution of the thrombosis, whereas among the neonates who did not reach the therapeutic level after 48 hours only 6/12 (50\%) had a complete resolution. No infants experienced bleeding related to therapy, even with anti-factor Xa levels greater than $1.0 \mathrm{U} / \mathrm{ml}$.

\section{Discussion}

It has been recognized that LMWH has an unpredictable anticoagulation effect in neonates because it has a wider volume of dis- tribution and decreased plasma level of antithrombin (8).

Our data support the fact that increased starting doses of enoxaparin are necessary in neonates with thrombosis to achieve anti factor Xa within 48 hours, as reported in recently published data $(9,10)$. Moreover, our preterm infants required a mean dose of 190 $\mathrm{UI} / \mathrm{kg}$ to achieve therapeutic antifactor Xa, slightly higher than term infants as even Dix et al. (11) suggetsed recently.

In this study, $80 \%$ of the neonates who were given LMWH according to published guidelines failed to reach target therapeutic anti-factor Xa levels within 48 hours, but $100 \%$ of neonates who were given a higher initial dosage of $175 \mathrm{UI} / \mathrm{kg}$ twice/day were able to reach it, without major or minor bleeding.

The time needed to reach a therapeutic anti-factor Xa level depended on the initial dosage of LMWH: the higher the starting dose, the shorter the time needed to reach a therapeutic anti-factor Xa level. An underestimated initial dosage of LMWH will expose the neonate to a higher number of venipunctures to monitor the plasma antifactor Xa level, before it reaches the correct valueA longer time will also be needed to attain therapeutic plasma anti-factor Xa level, leaving therefore the neonate for a certain period with a suboptimal therapy. As it is important to immediately obtain anticoagulation to treat thrombosis, it is mandatory that the therapeutic level of LMWH be reached as soon as possible. Furthermore as many small hospitals do not have the possibility to check plasma anti-factor Xa levels, it is important that they treat neonates with the correct dosage otherwise they will never reach the therapeutic level.

\section{Conclusion}

Although the use of enoxaparin has increased significantly in the last decades, large scale 
randomised controlled studies to establish its optimal dosage are lacking. This study was only retrospective and therefore we could not reach robust conclusions with respect to the relationship between the therapeutic dosage of enoxaparin and clot resolution, but our experience confirms the growing evidence that neonates have to be treated with a higher initial dose of enoxaparin to achieve target anticoagulation.

Authors' contributions: Conception and design: FP, $\mathrm{CA}$; Acquisition, analysis and interpretation of data: GP, FC; Drafting the article: MHL; Revising it critically for important intellectual content: AD.

Conflict of interest: The authors declare that they have no conflict of interest.

\section{References}

1. Nowak-Gottl U, von Kries R, Gobel U. Neonatal symptomatic thromboembolism in Germany: two year survey. Arch Dis Child Fetal Neonatal Ed. 1997;76: F163-F167.

2. Schmidt B, Andrew M. Neonatal thrombosis: report of a prospective Canadian and international registry. Pediatrics. 1995;96:939-43.

3. Hirsh J, Raschke R. Heparin and LMWH: the seventh ACCP Conference on antithrombotic and thrombolytic therapy. Chest. 2004;126(3):188203.

4. Malowany JI, Knoppert DC, Chan AK, Pepelassis $\mathrm{D}$, Lee DS. Enoxaparin use in the neonatal intensive care unit: experience over 8 years. Pharmacotherapy. 2007;27(9):1263-71.
5. Monagle P, Chalmers E, Chan A, DeVeber G, Kirkham F, Massicotte P, et al.; American College of Chest Physicians. Antithrombotic therapy in neonates and children: American College of Chest Physicians Evidence-Based Clinical Practice Guidelines (8th Edition). Chest. 2008;133(6 Suppl):887S-968S.

6. Monagle P, Chan AK, Goldenberg NA, Ichord RN, Journeycake JM, Nowak-Göttl U, et al.; American College of Chest Physicians. Antithrombotic therapy in neonates and children: Antithrombotic Therapy and Prevention of Thrombosis, 9th ed: American College of Chest Physicians Evidence-Based Clinical Practice Guidelines. Chest. 2012;141(2 Suppl):e737S-801S.

7. Michaels LA, Gurian M, Hegyi T, Drachtman RA. Low molecular weight heparin in the treatment of venous and arterial thromboses in the premature infant. Pediatrics. 2004;114(3):703-7.

8. Massicotte P, Adams M, Marzinotto V, Brooker LA, Andrew M. Low molecular weight heparin in pediatric patients with thrombotic disease: a dose finding study. J Pediatr. 1996;128:313-8.

9. Malowany JI, Monagle P, Knoppert DC, Lee DS, Wu J, McCusker P. Enoxaparin for neonatal trombosis: a call for a higher dose for neonates. Thromb Res. 2008; 122(6):826-30.

10. Sanchez de Toledo J, Gunawardena S, Munoz R, Orr R, Berry D, Sonderman S, et al. Do neonates, infants and young children need a higher dose of enoxaparin in the cardiac intensive care unit? Cardiol Young. 2010;20(2):138-43.

11. Dix D, Andrew M, Marzinotto V, Charpentier K, Bridge S, Monagle P, et al. The use of low molecular weight heparin in pediatric patients: a prospective cohort study. J Pediatr. 2000;136(4):439-45. 